TITLE:

\title{
Siloxane D4 capture by hydrophobic microporous materials
}

\section{AUTHOR(S):}

Mito-oka, Yasuko; Horike, Satoshi; Nishitani, Yusuke; Masumori, Tadao; Inukai, Munehiro; Hijikata, Yuh; Kitagawa, Susumu

\section{CITATION:}

Mito-oka, Yasuko ...[et al]. Siloxane D4 capture by hydrophobic microporous materials. Journal of Materials Chemistry A 2013, 1(27): 7885-7888

ISSUE DATE:

2013-05

URL:

http://hdl.handle.net/2433/189851

\section{RIGHT:}

This journal is (C) The Royal Society of Chemistry 2013; この論文は出版 社版でありません。引用の際には出版社版をご確認ご利用ください。; This is not the published version. Please cite only the published version. 


\title{
Siloxane D4 Capture by Hydrophobic Microporous Materials
}

\author{
Yasuko Mito-oka, ${ }^{a}$ Satoshi Horike, ${ }^{\text {bc }}$ Yusuke Nishitani, ${ }^{\text {a }}$ Tadao Masumori, ${ }^{\text {a }}$ Munehiro Inukai, ${ }^{\text {d }}$ Yuh Hi- \\ jikata, ${ }^{a}$ Susumu Kitagawa*b,d \\ ${ }^{a}$ Research Center, Toyobo Co., Ltd., 2-1-1, Katata, Otsu, Shiga 520-0292, Japan \\ ${ }^{b}$ Department of Synthetic Chemistry and Biological Chemistry, Graduate School of Engineering, Kyoto University, Katsura, \\ Nishikyo-ku, Kyoto 615-8510, Japan. \\ ${ }^{c}$ PRESTO, Japan Science and Technology Agency (JST), Kawaguchi, Saitama 332-0012, Japan. \\ ${ }^{d}$ Institute for Integrated Cell-Material Sciences (iCeMS), Kyoto University, Yoshida, Sakyo-ku, Kyoto 606-8501, Japan. \\ KEYWORDS (Word Style "BG_Keywords").
}

Supporting Information Placeholder

\begin{abstract}
Porous substances, including crystalline coordination materials and an amorphous organic polymer, were studied for their selective adsorption of siloxane D4. The investigated materials demonstrated a level of uptake comparable to that of conventional activated carbon.
\end{abstract}

Biogas generally includes methane and carbon dioxide mixtures produced by anaerobic digestion of waste materials. In biogas, the presence of impurities, such as sulfide, halide, and polysiloxane compounds, is a problem because they hinder the purification of methane, which is required for its further use. Several techniques have been developed to remove siloxane, one of the major impurities, from biogas. ${ }^{1}$ Adsorption on porous activated carbon represents a common practice. However, it is difficult to completely regenerate the activated carbon after the capture of siloxanes because of their strong binding. Furthermore, the co-adsorption of siloxanes and water occurs under humid conditions. Thus, the development of new porous adsorbents for siloxanes is significant. Among the siloxanes in biogas, octamethylcyclotetrasiloxane (siloxane D4, Figure 1a) is highly abundant. In this study, we investigated the selective capture of siloxane D4 by several organic/inorganic microporous compounds.

Porous coordination polymers (PCPs), or metal-organic frameworks (MOFs), and covalent organic frameworks (COFs) have been developed in the last decade. ${ }^{2}$ These are constructed via coordination or covalent bonds. They have a large surface area and diverse, functional chemical substituents, and are studied for gas storage, separations, and catalysis. There are many reports on the $\mathrm{CO}_{2}$ separation over $\mathrm{CH}_{4}$ by use of these materials. ${ }^{20,3}$ On the other hand, to the best of our knowledge, there are no reports on siloxane adsorption by these compounds, even though both of the separation technologies are important to purify $\mathrm{CH}_{4}$ from biogas. We focused on siloxane D4, which has a high boiling point (448 K), strong hydrophobicity, and low polarity. Here we employed $\left[\mathrm{Zn}_{4} \mathrm{O}(\mathrm{bdc})(\mathrm{bpz})_{2}\right]$ (bdc, 1,4-benzenedicarboxylate; bpz, 3,3',5,5'tetramethyl-4,4'-bipyrazolate) ${ }^{4}[\mathrm{Al}(\mathrm{OH})(2,6-\mathrm{ndc})](2,6-\mathrm{ndc}, 2,6$ naphthalenedicarboxylate; DUT-4); ${ }^{5}$ and amorphous, porous organic framework poly $\left(4,4^{\prime}\right.$-biphenylene)silane (EOF-2) ${ }^{6}$ because of their hydrophobicity and large surface area. A conventional activated carbon species was also studied for comparison. a

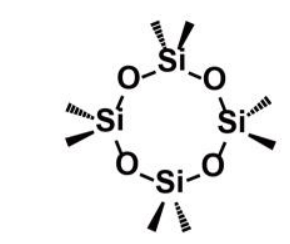

b
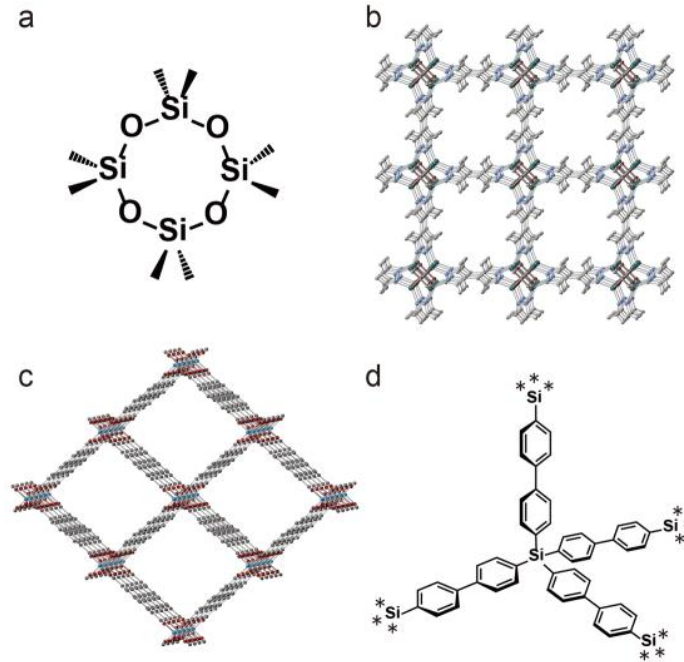

d

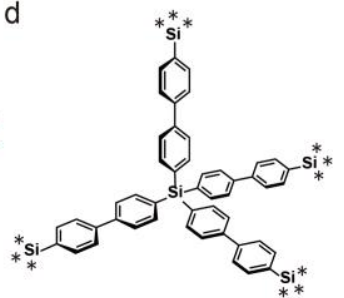

Figure 1. Structures of (a) siloxane $\mathrm{D} 4$, (b) $\left[\mathrm{Zn}_{4} \mathrm{O}(\mathrm{bdc})(\mathrm{bpz})_{2}\right]$, (c) $[\mathrm{Al}(\mathrm{OH})(2,6-\mathrm{ndc})]$ (DUT-4), and (d) poly(4,4'-biphenylene)silane (EOF-2)

Structures of the porous compounds are shown in Figure 1. We characterized the hydrophobicity of the compounds by a water vapor adsorption experiment. Each sample was activated and exposed to water vapor at $30{ }^{\circ} \mathrm{C}$ and $60 \%$ relative humidity for $3 \mathrm{~h}$ under the control of a thermohygrostat. We then evaluated the amount of adsorbed water from the change in weight. The amount of adsorbed water vapor was found to be $5.2,8.2$, and $0.3 \mathrm{wt} \%$ for $\left[\mathrm{Zn}_{4} \mathrm{O}(\mathrm{bdc})(\mathrm{bpz})_{2}\right]$, DUT-4, and EOF-2, respectively. These levels are comparable to that of activated carbon (3.8 wt \%), which was prepared under the same conditions. Only small quantities of $\mathrm{H}_{2} \mathrm{O}$ were adsorbed because of their hydrophobicity, especially in the case of EOF-2. For this species, the hydrophobic moiety poly $(4,4$ 'biphenylene)silane is responsible for the framework's hydrophobicity. 
For the selective adsorption of siloxane D4 from biogas, coadsorption of not only moisture but also other gases, such as $\mathrm{CO}_{2}$ and $\mathrm{CH}_{4}$, by the adsorbents must be prevented. Adsorption isotherms of $\mathrm{CO}_{2}$ and $\mathrm{CH}_{4}$ at $298 \mathrm{~K}$ were measured. Activated carbon shows a Langmuir-type isotherm for $\mathrm{CO}_{2},{ }^{7}$ and the total amount adsorbed reaches $51 \mathrm{mLg}^{-1}$ at $101 \mathrm{kPa}$. The other three compounds show linear type isotherms, and their adsorption levels are less than $40 \mathrm{mLg}^{-1}$. In case of $\mathrm{CH}_{4}$, all four compounds show low levels of adsorption (less than $20 \mathrm{mLg}^{-1}$ at $101 \mathrm{kPa}$ ). Linear isotherms indicate low affinity between the gases and porous frameworks at 298 $\mathrm{K}$. The adsorption behavior is therefore suitable for selective adsorption of siloxane D4 in the presence of the other impurities.

We estimated the adsorption capacity of these compounds for siloxane D4 by a TGA study. Since siloxane D4 has low volatility, we could not use conventional gas adsorption instruments. TGA profiles for samples that were activated and exposed to siloxane D4 vapor at $30{ }^{\circ} \mathrm{C}$ for $3.5 \mathrm{~h}$ were measured. Activated carbon adsorbs approximately $20 \mathrm{wt} \%$ siloxane D4, and desorption is observed in the temperature range $200-300{ }^{\circ} \mathrm{C}$. The other compounds show various sorption characteristics. DUT-4 adsorbs $15 \mathrm{wt} \%$ of siloxane D4. This framework strongly confines the molecules, and its release temperature is over $250{ }^{\circ} \mathrm{C}$. Such stable confinement is not amenable to the desorption of siloxane D4 using a low regeneration energy. On the other hand, $\left[\mathrm{Zn}_{4} \mathrm{O}(\mathrm{bdc})(\mathrm{bpz})_{2}\right]$ and EOF-2 show gradual release beginning near room temperature, and adsorption uptakes of $30 \mathrm{wt} \%$ for $\left[\mathrm{Zn}_{4} \mathrm{O}(\mathrm{bdc})(\mathrm{bpz})_{2}\right]$ and $13 \mathrm{wt} \%$ for EOF-2 are observed. XRD pattern of $\left[\mathrm{Zn}_{4} \mathrm{O}(\mathrm{bdc})(\mathrm{bpz})_{2}\right]$ after removal of the adsorbed siloxane D4 was same as the initial state, and it indicates its crystallinity is retained via the sorption of siloxane D4. The BET surface area of activated carbon is $1050 \mathrm{~m}^{2} \mathrm{~g}^{-1}$, and those of $\left[\mathrm{Zn}_{4} \mathrm{O}(\mathrm{bdc})(\mathrm{bpz})_{2}\right]$, DUT-4, and EOF-2 are approximately 1500 , 1300 , and $1000 \mathrm{~m}^{2} \mathrm{~g}^{-1}$ respectively. The total uptake of siloxane D4 is dependent on the surface area. Consequently, we confirmed strong hydrophobicity, low adsorption of $\mathrm{CO}_{2}$ and $\mathrm{CH}_{4}$ gases, and satisfactory siloxane D4 uptake for $\left[\mathrm{Zn}_{4} \mathrm{O}(\mathrm{bdc})(\mathrm{bpz})_{2}\right]$ and EOF-2. These two compounds release adsorbed siloxane D4 at a temperature lower than that of activated carbon, and are promising materials with regard to both selectivity and energy consumption for regeneration. During the siloxane adsorption and desorption experiments, these structures did not change, as determined by powder Xray diffraction and solid state NMR measurements.

To investigate the spectral properties of the adsorbed siloxane D4 in the porous compounds, we performed solid state ${ }^{29} \mathrm{Si}$ NMR measurements (Figure 2). The peak for bulk siloxane D4 appears at -19.2 ppm. $^{8}$ The chemical shift of the Si atoms in EOF-2 is observed at $-14.9 \mathrm{ppm}$, whereas in the original report, it was observed at -17.9 ppm. ${ }^{6}$ The difference in the chemical shift is due to the amorphous nature of the framework. The peak for siloxane D4 adsorbed in these compounds is sharp because of isotropic motion. The chemical shift of this peak varies among EOF-2, $\left[\mathrm{Zn}_{4} \mathrm{O}(\mathrm{bdc})(\mathrm{bpz})_{2}\right]$, and DUT-4 (-19.2, -21.6, and $-24.5 \mathrm{ppm}$, respectively). The peak in EOF-2 is the same as that in bulk siloxane D4, which indicates a weak host-guest interaction. A higher upfield shift corresponds to an increase in this interaction, thus indicating that DUT-4 has the highest affinity for siloxane D4. This corresponds to the TGA result, which showed that the release temperature for DUT-4 was the highest of all compounds. The DUT-4 spectrum also shows a small fractional shoulder at $-23 \mathrm{ppm}$. This is attributed to the variable environment of siloxane D4 in the pores.

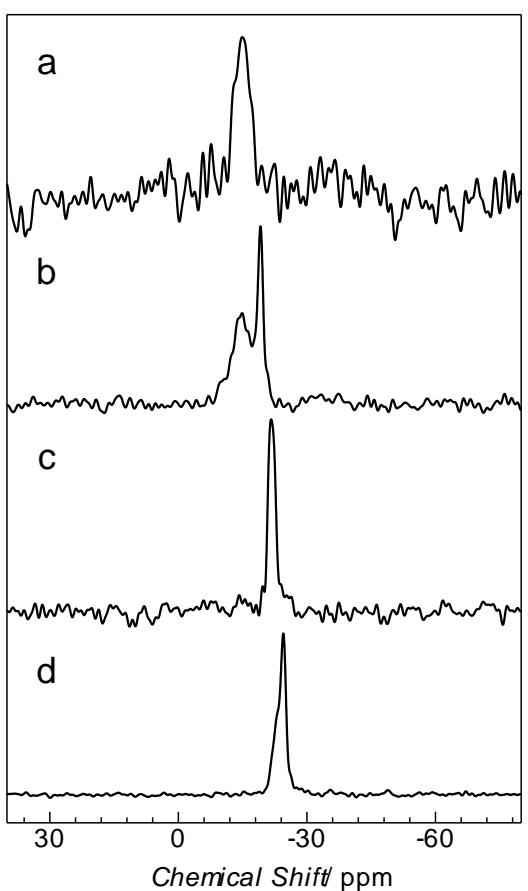

Figure 2. Solid state ${ }^{29} \mathrm{Si}$ MAS NMR spectra of (a) EOF-2 framework exclusively and frameworks with adsorbed siloxane D4: (b) EOF-2, (c) [ $\left.\mathrm{Zn}_{4} \mathrm{O}(\mathrm{bdc})(\mathrm{bpz})_{2}\right]$, and (d) DUT-4.

The interaction between siloxane D4 and the framework depends on the porosity of the structures. The framework of $\left[\mathrm{Zn}_{4} \mathrm{O}(\mathrm{bdc})(\mathrm{bpz})_{2}\right]$ has 3-D connected channels with a bottle-andneck-type shape, and DUT-4 has 1-D straight channels with a rhombic shape. We assume that the stronger interaction of siloxane D4 with DUT-4 results from a more uniform match between the shapes of the guest molecule and the pore. We studied the adsorption mechanism of siloxane D4 in the pore by molecular mechanic calculations (Figures S6 and S7). Even though we employed various conformations as the initial structure, the methyl groups of siloxane D4 preferably directed to the corners of the rhombic pore shape of DUT-4 in all the optimized structures. We then considered that the rectangular shape of siloxane D4 could fit to the pore shape, generating strong interactions. On the other hand, in $\left[\mathrm{Zn}_{4} \mathrm{O}(\mathrm{bdc})(\mathrm{bpz})_{2}\right]$, siloxane $\mathrm{D} 4$ has a more isotropic nature, consistent with the observation of gradual desorption from lower temperatures.

We studied the selective adsorption properties of the frameworks under not only gas equilibrium conditions but also kinetic (gas flowing) conditions. The gas comprising siloxane D4 (5 ppm) in air at $50 \%$ relative humidity and $25{ }^{\circ} \mathrm{C}$ was used to evaluate the selective sorption properties. Breakthrough curves of the compounds are shown in Figure 3. The gas mixture (pressure, $101 \mathrm{kPa}$ and flow rate, $0.5 \mathrm{~L} \mathrm{~min}^{-1}$ ) was passed through a column filled with $100 \mathrm{mg}$ of activated powder samples. We monitored the time-dependent concentration of siloxane D4 in the outlet gas to estimate the efficiency of removal. All the compounds show over 95\% removal efficiency initially, and this level gradually decreases as the amount of adsorbed material increases. The EOF-2 framework shows a profile similar to that of activated carbon, and the observed removal efficiency is reduced to approximately $70 \%$ at $500 \mathrm{~min}$. On the other hand, $\left[\mathrm{Zn}_{4} \mathrm{O}(\mathrm{bdc})(\mathrm{bpz})_{2}\right]$ and DUT-4 show better performance. The decays of removal efficiency after 300 minutes for these compounds are smaller than that of EOF-2. Even after $1000 \mathrm{~min}$, the observed efficiencies are over $70 \%$, which indicates their effective 
adsorption of siloxane D4. If the compounds preferably adsorb water vapor than siloxane D4, the removal efficiency would decay more rapidly because of water adsorption. The retention of the high efficiency of siloxane D4 removal by $\left[\mathrm{Zn}_{4} \mathrm{O}(\mathrm{bdc})(\mathrm{bpz})_{2}\right]$ and DUT4 suggests that they have strong selectivity for siloxane D4 even under high humidity conditions. The high level of selectivity is attributed to their strong hydrophobicity and optimal chemical interaction with siloxane D4, leading to high uptake. The EOF-2 framework also exhibits high hydrophobicity; however, the breakthrough curve shows a rapidly decreasing profile because of its weaker interaction with siloxane D4, as suggested by TGA and NMR studies.

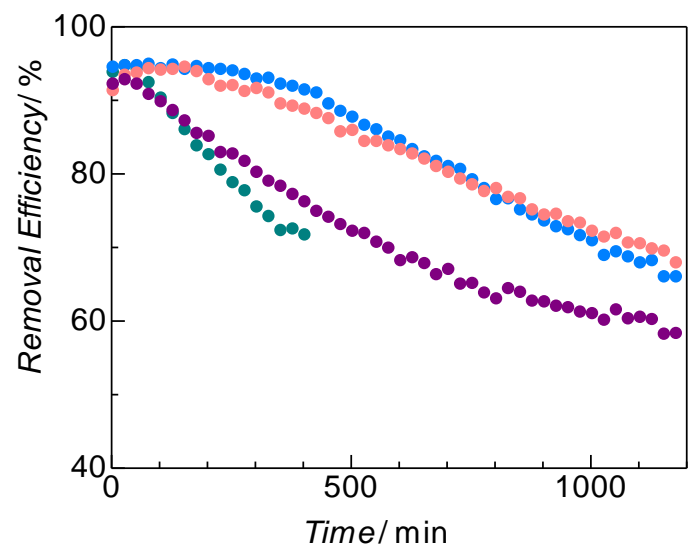

Figure 3. Breakthrough curves of siloxane D4 for $\left[\mathrm{Zn}_{4} \mathrm{O}(\mathrm{bdc})(\mathrm{bpz})_{2}\right]$ (pink), DUT-4 (blue), EOF-2 (purple), and activated carbon (green) at room temperature. The flue gas composition is siloxane D4 (5 ppm) in air at $50 \%$ relative humidity and $298 \mathrm{~K}$. The flow rate is $0.5 \mathrm{~L} \mathrm{~min}^{-1}$, and the space velocity is $100,000 \mathrm{~h}^{-1}$.

In conclusion, we investigated three microporous compounds, [ $\left.\mathrm{Zn}_{4} \mathrm{O}(\mathrm{bdc})(\mathrm{bpz})_{2}\right]$, DUT-4, and EOF-2, to evaluate their selective adsorption of siloxane D4. Results for their adsorption of water, $\mathrm{CO}_{2}$, and $\mathrm{CH}_{4}$, which are found in biogas, suggested the hydrophobic nature of these frameworks and further indicated that they have only weak interactions with these gases under ambient temperature and pressure. Both equilibrium and kinetic studies of the selective adsorption of siloxane D4 indicated that these frameworks have a level of efficiency comparable with that of conventional activated carbon. Among these compounds, $\left[\mathrm{Zn}_{4} \mathrm{O}(\mathrm{bdc})(\mathrm{bpz})_{2}\right]$ is one of the best candidates for the selective adsorption of siloxane D4 at ppm levels under gas flowing conditions. As a future work, we will employ the mixture gas having the exactly same composition of biogas to evaluate the performance of the selectivity for these compounds. These results encourage further studies toward the design of new porous materials for selective removal of various volatile organic compounds, including the family of siloxane molecules, from biogas mixtures under humid conditions.

\section{ASSOCIATED CONTENT}

Synthesis of compounds, gas adsorption experiments, TGA, XRD, molecular mechanics calculation.

\section{AUTHOR INFORMATION}

\section{Corresponding Author}

Prof. Susumu Kitagawa

E-mail address: kitagawa@icems.kyoto-u.ac.jp

Fax: +81-75-383-2732; Tel: +81-75-383-2736

\section{Author Contributions}

The manuscript was written through contributions of all authors.

\section{Funding Sources}

This work was supported by New Energy and Industrial Technology Development Organization (NEDO) and by Japan Science and Technology Agency PRESTO program, Grants-in-Aid for Scientific Research, Japan Society for the Promotion of Science (JSPS). iCeMS is supported by World Premier International Research Initiative (WPI), MEXT, Japan.

\section{REFERENCES}

(1) (a) Finocchio, E.; Montanari, T.; Garuti, G.; Pistarino, C.; Federici, F.; Cugino, M.; Busca, G. Energy \& Fuels 2009, 23, 4156; (b) Montanari, T.; Finocchio, E.; Bozzano, I.; Garuti, G.; Giordano, A.; Pistarino, C.; Busca, G. Chem. Eng. J. 2010, 165, 859.

(2) (a) Eddaoudi, M.; Moler, D. B.; Li, H. L.; Chen, B. L.; Reineke, T. M.; O'Keeffe, M.; Yaghi, O. M. Acc. Chem. Res. 2001, 34, 319; (b) Kitagawa, S.; Kitaura, R.; Noro, S. Angew. Chem. Int. Ed. 2004, 43, 2334; (c) Bradshaw, D.; Claridge, J. B.; Cussen, E. J.; Prior, T. J.; Rosseinsky, M. J. Acc. Chem. Res. 2005, 38, 273; $\quad$ (d) El-Kaderi, H. M.; Hunt, J. R.; Mendoza-Cortes, J. L.; Cote, A. P.; Taylor, R. E.; O'Keeffe, M.; Yaghi, O. M. Science 2007, 316, 268; $\quad$ (e) Férey, G. Chem. Soc. Rev. 2008, 37, 191; (f) Morris, R. E.; Wheatley, P. S. Angew. Chem. Int. Ed. 2008, 47, 4966; (g) Shimizu, G. K. H.; Vaidhyanathan, R.; Taylor, J. M. Chem. Soc. Rev. 2009, 38, 1430; $\quad$ (h) Wang, Z. Q.; Cohen, S. M. Chem. Soc. Rev. 2009, 38, 1315; $\quad$ (i) Murray, L. J.; Dincă, M.; Long, J. R. Chem. Soc. Rev. 2009, 38, 1294; $\quad$ (j) Zhang, J. P.; Huang, X. C.; Chen, X. M. Chem. Soc. Rev. 2009, 38, 2385; (k) Hupp, J. T.; Farha, O. K. Acc. Chem. Res. 2010, 43, 1166; (l) Holst, J. R.; Trewin, A.; Cooper, A. I. Nat. Chem. 2010, 2, 915; (m) Della Rocca, J.; Liu, D. M.; Lin, W. B. Acc. Chem. Res. 2011, 44, 957; $\quad$ (n) Zhou, H. C.; Long, J. R.; Yaghi, O. M. Chem. Rev. 2012, 112, 673; (o) Sumida, K.; Rogow, D. L.; Mason, J. A.; McDonald, T. M.; Bloch, E. D.; Herm, Z. R.; Bae, T. H.; Long, J. R. Chem. Rev. 2012, 112, 724.

(3) Li, J. R.; Kuppler, R. J.; Zhou, H. C. Chem. Soc. Rev. 2009, 38, 1477

(4) Hou, L.; Lin, Y. Y.; Chen, X. M. Inorg. Chem. 2008, 47, 1346.

(5) Senkovska, I.; Hoffmann, F.; Froba, M.; Getzschmann, J.; Bohlmann, W.; Kaskel, S. Micropor. Mesopor. Mater. 2009, 122, 93.

(6) Rose, M.; Bohlmann, W.; Sabo, M.; Kaskel, S. Chem. Commun. $2008,2462$.

(7) Sing, K. S. W.; Everett, D. H.; Haul, R. A. W.; Moscou, L.; Pierotti, R. A.; Rouquerol, J.; Siemieniewska, T. Pure Appl. Chem. 1985, 57, 603.

(8) (a) Zhang, Z. P.; Gorman, B. P.; Dong, H. J.; Orozco-Teran, R. A.; Mueller, D. W.; Reidy, R. F. J. Sol-Gel Sci. Tech. 2003, 28, 159; (b) Casserly, T. B.; Gleason, K. K. J. Phys. Chem. B 2005, 109, 13605. 